\title{
Pollution evaluation in the Shahrood River: do physico-chemical and macroinvertebrate-based indices indicate same responses to anthropogenic activities?
}

\begin{abstract}
This study evaluates the impact of anthropogenic activities on the Shahrood River using water physico-chemical variables and macroinvertebrates data sets obtained over a period of 12 months between February 2012 and February 2013 at 8 sampling sites. Biotic indices i.e. FBI and BMWP based on macroinvertebrates and physico-chemical indices (MPI, HPI and NSF-WQI) were employed to evaluate the water quality status in connection with naturaland human-induced pressures. Based on physico-chemical indices, water quality was categorized as low polluted level and it is suitable for drinking purposes. The water quality based on biotic indices was related to the anthropic activities; a clear deterioration of the water quality was observed from upstream to downstream sites. The water quality along the river changed from very good (class I; reference sites) to good (class II; midstream sites) and turned into moderate (class III) and poor (class IV) quality (downstream sites). These findings indicate that biotic indices are more powerful indicators in assessing water quality than physico-chemical indices. Allocapnia, Glossosoma and Hesperoperla were exclusively related to least disturbed sites, and Naididae, Orthocladiinae and Ecdyonurus were found in sites showing notable degradation. Our results recommended that the use of macroinvertebrates could be employed as a cost-effective tool for biomonitoring and controlling of polluted riverine ecosystems in the Middle East. Finally, the results from this study may be useful not only for developing countries, but also for any organization struggling to use macroinvertebrate based indices with restricted financial resources and knowledge.
\end{abstract}

Keyword: Bioindicator; Macroinvertebrate; Pollution; Physico-chemical indices; Heavy metals 